Int. J. Odontostomat., 4(2):189-196, 2010.

\title{
Carcinoma Sebáceo/Mioepitelial de Parótida: Análisis Histopatológico e Inmunohistoquímico
}

\author{
Sebaceous Epithelial Myoepithelial Carcinoma of Parotid: \\ Histopathological and Immunohistochemical Analysis
}

Samar María Elena; Avila Rodolfo Esteban; Fonseca Ismael Bernardo \& Ferraris Ricardo Virgilio

SAMAR, M. E.; ÁVILA, R. E.; FONSECA, I. B. \& FERRARIS, R. V. Carcinoma sebáceo/mioepitelial de parótida: Análisis histopatológico e inmunohistoquímico. Int. J. Odontostomat., 4(2):189-196, 2010.

RESUMEN: El carcinoma epitelial-mioepitelial (CEM) de glándulas salivales es un tumor maligno bifásico de bajo grado, que comprende aproximadamente el $1 \%$ de todos los tumores salivales. Se describe un raro caso de CEM sebáceo de glándula parótida en un hombre al que se le realizó parotidectomía izquierda por formación tumoral aparentemente encapsulada. Para su estudio histopatológico e inmunohistoquímico el material se coloreó con H/E, tricrómicos de Masson y Dane/Azul alciano, PAS/H, Azul de toluidina, antígeno epitelial de membrana (EMA), citoqueratinas (CK) de bajo peso molecular, a actina de músculo liso (a-SMA) y S-100. Los cortes histológicos mostraron un patrón multinodular con nidos tumorales constituidos por estructuras tubulares delimitadas por: a-células acidófilas luminales cuboideas; b- células claras adluminales. Las células ductales luminales se marcaron positivamente con los anticuerpos para EMA y CK. Se observó inmunorreactividad positiva para a-SMA y S-100 en las células claras. Se observaron áreas de diferenciación sebácea dentro de la masa tumoral.

Los estudios inmunohistoquímicos confirman la presencia de células tumorales ductales y mioepiteliales. Además, las células claras mioepiteliales constituyen un elemento importante para el diagnóstico diferencial entre CEM sebáceo y adenocarcinoma sebáceo.

PALABRAS CLAVE: parótida, carcinoma epitelial-mioepitelial, histopatología, inmunohistoquímica

\section{INTRODUCCIÓN}

El carcinoma epitelial/mioepitelial (CEM) de glándulas salivales es un tumor maligno bifásico de bajo grado de malignidad. Se ha postulado que deriva de los conductos intercalares de las glándulas salivales ya que su patrón tubular reproduce este fenotipo (Sheetala et al., 2007). Comprende menos del 1\% de todos los tumores salivales (Batzakis et al., 1992; M'Sakni et al., 2007), siendo la parótida su localización más frecuente, con una morbilidad relativamente baja ( $\mathrm{Ta}_{\mathrm{s}}$ s et al., 2003; Sheetala et al., 2007; Maurer et al., 2009). La mayoría de los CEM ocurre entre la $6^{\circ}$ y $7^{\circ}$ décadas y cerca del $60 \%$ de los pacientes son mujeres (Maurer et al., 2009).

Algunos tumores se desarrollan ocasionalmente en submaxilar (Erkan et al., 2007) y glándulas salivales menores (Puri et al., 2004; Jain et al., 2006; Kumai et al., 2006; Teppo \& Paronen, 2008; Angiero et al., 2009). Esta neoplasia puede afectar otros sitios anatómicos donde hay glándulas, como bronquios, pulmones, útero, fosas y senos nasales (Batzakis et al., 1992; Lee et al., 2000; Senis-Segarra et al., 2002; Doganay et al., 2003; Kuran et al., 2008; Okudela et al., 2010). Mikaelian et al. (1986) describieron un CEM desarrollado en la región subglótica, con un patrón infiltrante y destructivo.

EI CEM fue descrito por primera vez por Donath et al. (1972), en Alemania y se lo reconoció como una entidad patológica diferente en la Segunda Revisión de la Clasificación Histológica Internacional de Tumores de las Glándulas Salivales (Seifert \& Sobin, 1991; Tralongo \& Daniele, 1998; Ustinova et al., 2004).

II Cátedra de Histología, Embriología y Genética. Facultad de Ciencias Médicas. Cátedra A de Histología y Embriología. Facultad de Odontología. Universidad Nacional de Córdoba. Argentina. samarcongreso@gmail.com

Subsidio bianual SECYT 05/H249. Secretaría de Ciencia y Tecnología. Universidad Nacional de Córdoba. Argentina. 
Basándose en su apariencia histológica y su comportamiento biológico Lampe et al postularon en 1981 que el CEM es una variante rara del carcinoma adenoide quístico (Lampe et al., 1981).

EI CEM presenta agresividad regional y tendencia a recidivar localmente (Batzakis et al, 1992; Gimeno Aranguez y Lacruz Pelea, 2001; Kawahara et al, 2005). Su estructura histológica muestra un patrón de crecimiento sólido y tubular, con una población celular bifásica que incluye una capa interna de células epiteliales y una externa de células mioepiteliales (Thiébault et al., 1999; Ellis y Auclair, 2008; Shinozaki et al., 2008; Robinson, 2010).

En el presente reporte describimos un raro caso de carcinoma sebáceo epitelial/mioepitelial de glándula parótida, estudiado con métodos histológicos, histoquímicos e inmunohistoquímicos.

\section{MATERIAL Y MÉTODO}

Paciente de 70 años, de sexo masculino, con formación tumoral de $3 \times 3 \times 3 \mathrm{~cm}$ en región parotídea izquierda aparentemente encapsulada, siendo al corte de color blanquecino-amarillento y consistencia firme. Para su estudio histopatológico e inmunohistoquímico (Samar et al., 2004) el material se coloreó con:

A- $H / E$, tricrómico de Masson yDane/Azul alciano, $\mathrm{PAS} / \mathrm{H}$ y PAS/diastasa, Azul de toluidina.

B- $\quad$ Antígeno epitelial de membrana (EMA) y citoqueratinas (CK) de bajo peso molecular para marcación de células epiteliales luminales.

C- a actina de músculo liso (a-SMA) y S-100 para marcación de células mioepiteliales adluminales.

\section{RESULTADOS}

Los cortes histológicos mostraron un patrón de crecimiento multinodular con nidos tumorales separados por bandas de tejido conectivo fibroso de diferente espesor enalgunas zonas o por septos acidófilos hialinos tipo membrana basal en otras. Las masas tumorales estaban constituidas por estructuras tubulares cuyas luces estaban delimitadas por dos capas celulares bien diferenciadas con técnicas histológicas habituales: a- La capa que delimitaba la luz tubular presentaba células acidófilas luminales

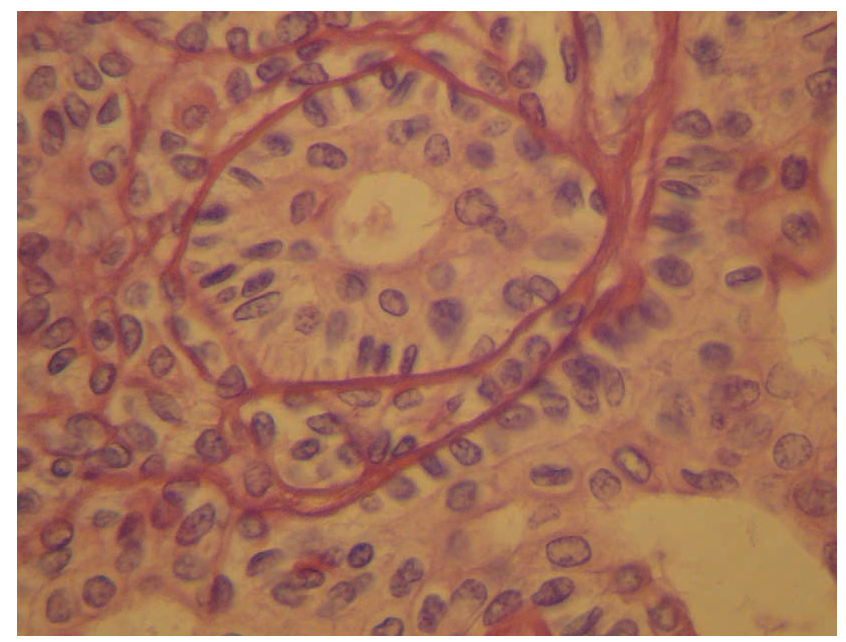

Fig. 1. Nidos tumorales de estructura tubular separados por septos acidófilos hialinos revestidos por células luminales y adluminales. Coloración H/E. 400x

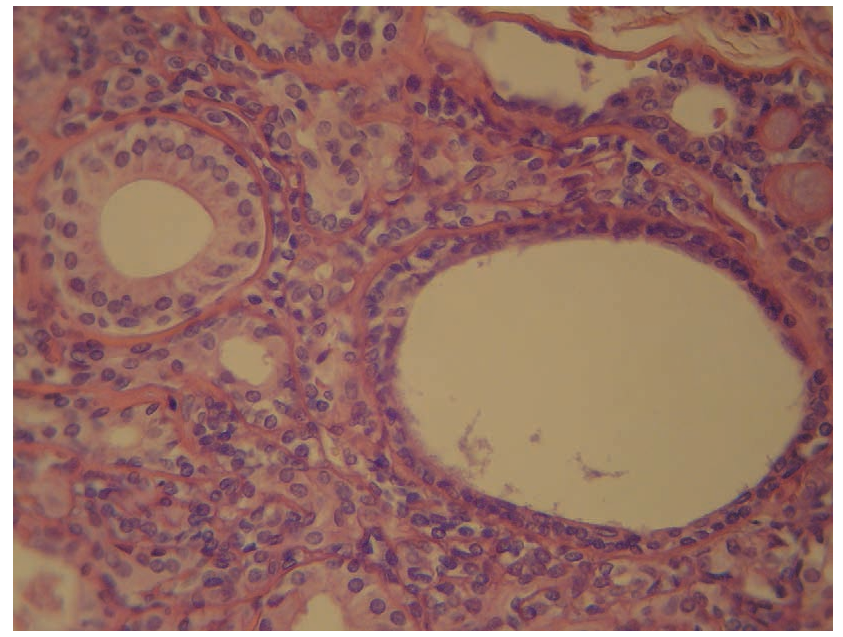

Fig. 2. La imagen muestra a la derecha un túbulo de aspecto quístico. Coloración H/E. 400x.

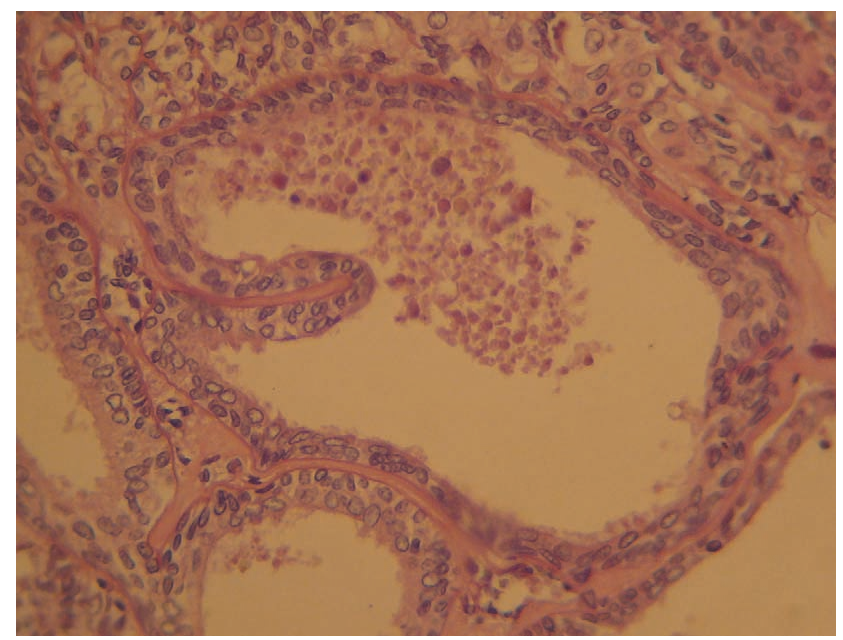

Fig. 3. Túbulo con una proyección papilar hacia el interior de la luz. Coloración H/E. 400x. 


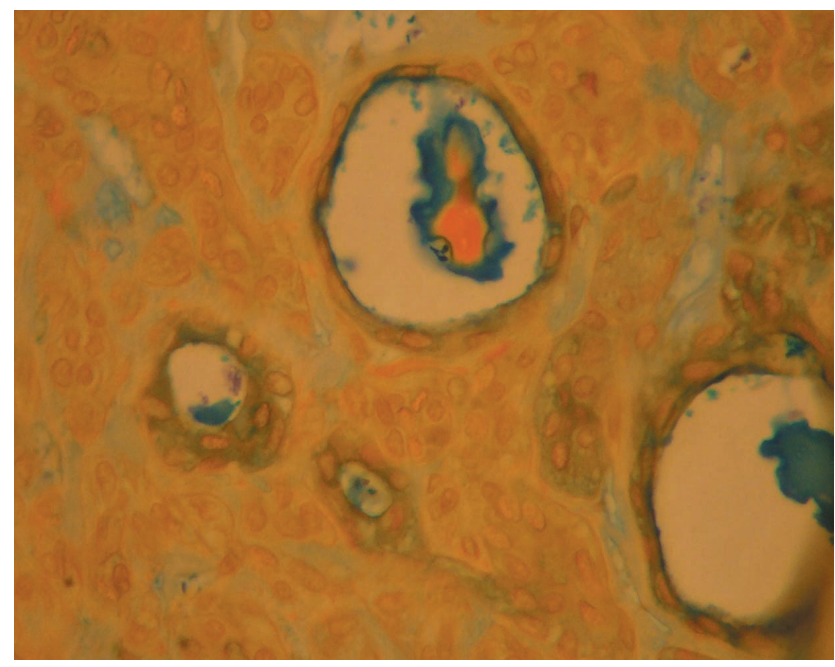

Fig. 4. Se observan en las luces tubulares material alcianófilo. Tricrómico de Dane/Azul alciano. 400x.

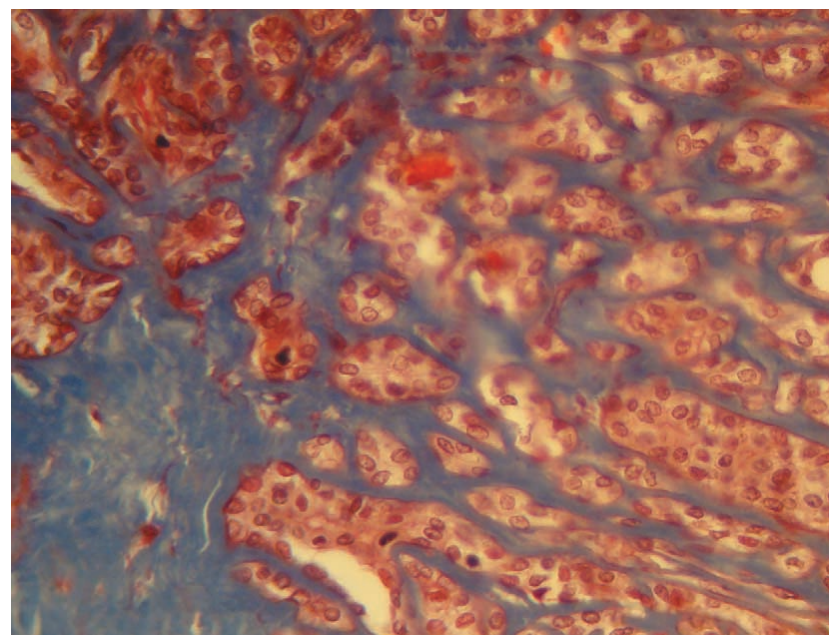

Fig. 5. Tejido conectivo fibroso coloreado de azul con tricrómico de Masson. 100x.

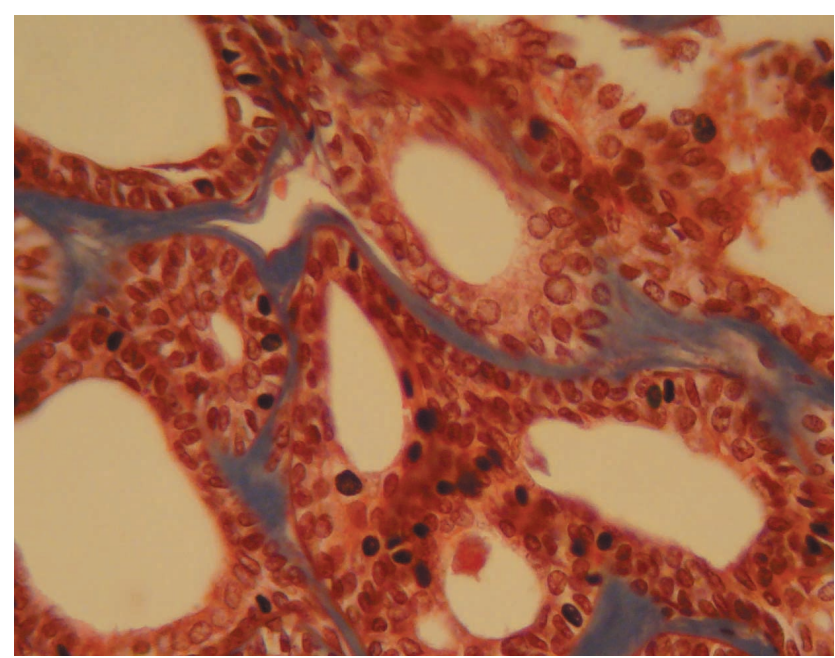

Fig. 6. Detalle a mayor aumento de la Figura 5. 400x. cuboideas, con núcleos redondeados y uniformes que ocupaban casi todo el citoplasma; b- Las células de la capa adluminal eran claras, poligonales y de tamaño variable pero más grandes que las células luminales (Fig. 1). En pocos túbulos las luces tomaban un aspecto quístico y ocasionalmente aparecían proyecciones papilares delicadas (Figs. 2 y 3 ).

Algunas luces ductales estan ocupadas por una sustancia acidófila, PAS positiva diastasa resistente y Azul alciano positiva (Fig. 4).

Se observaron atipias nucleares aisladas al igual que las mitosis ( 1 a 2 mitosis por 10 campos de mayor aumento). El tejido conectivo fibroso se coloreaba intensamente de azul con tricrómico de Masson indicativo de su componente colágeno y las áreas hialinas eran

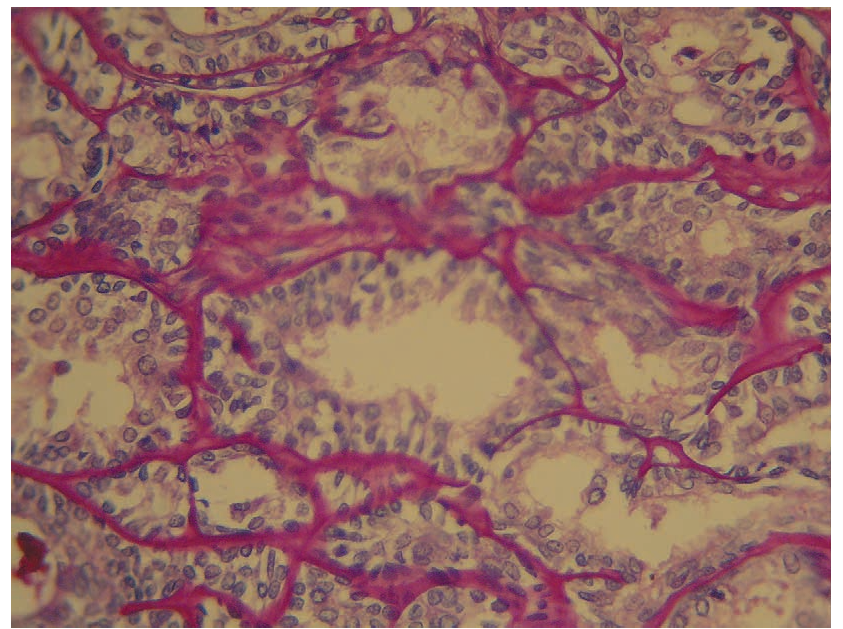

Fig. 7. Areas intertubulares hialinas fuertemente PAS positivas. Coloración PAS/H. 400x.

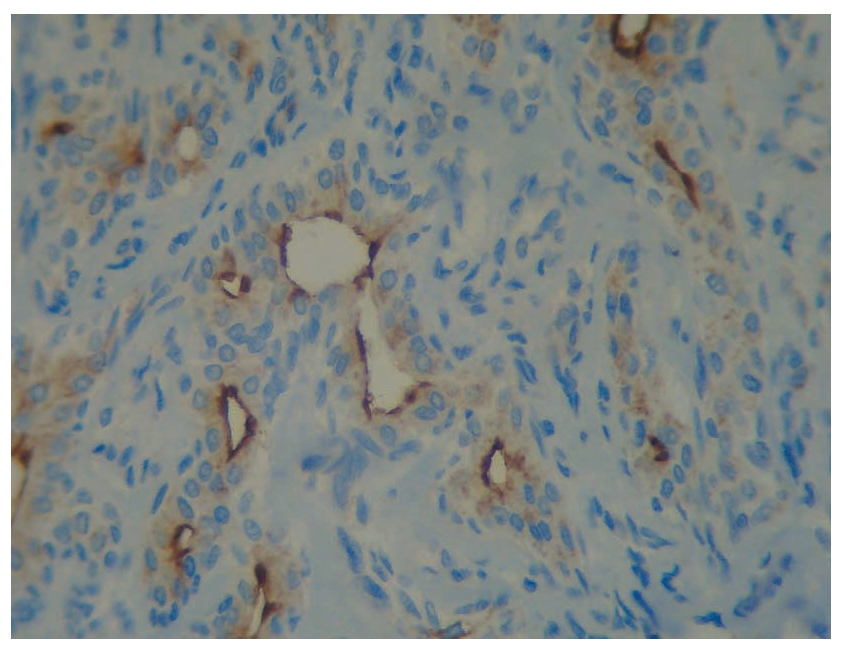

Fig. 8. Marcación positiva de células epiteliales luminales para EMA. 100x. 
fuertemente PAS reactivas (Figs. 5, 6, y 7). El citoplasma de las células claras presentaba granulaciones PAS positivas sensibles a la acción enzimática de diastasa. Las células ductales se marcaron positivamente con los anticuerpos para EMA y CK de bajo peso molecular, pero resultaron negativas para S-100 y a-SMA. Se destacó inmunorreactividad fuertemente positiva para aSMA y S-100 en las células claras y negatividad para EMA y CK de bajo peso molecular (Figs. 8, 9, 10 y 11).

No se observó infiltración perineural ni invasión vascular. Los márgenes quirúrgicos estaban libres de células tumorales.

Un hallazgo peculiar fue la presencia de múltiples áreas de diferenciación sebácea distribuida focalmente en la masa tumoral (Fig. 12). Los sebocitos mostraban núcleos picnóticos y un citoplasma pálido repleto de vacuolas.

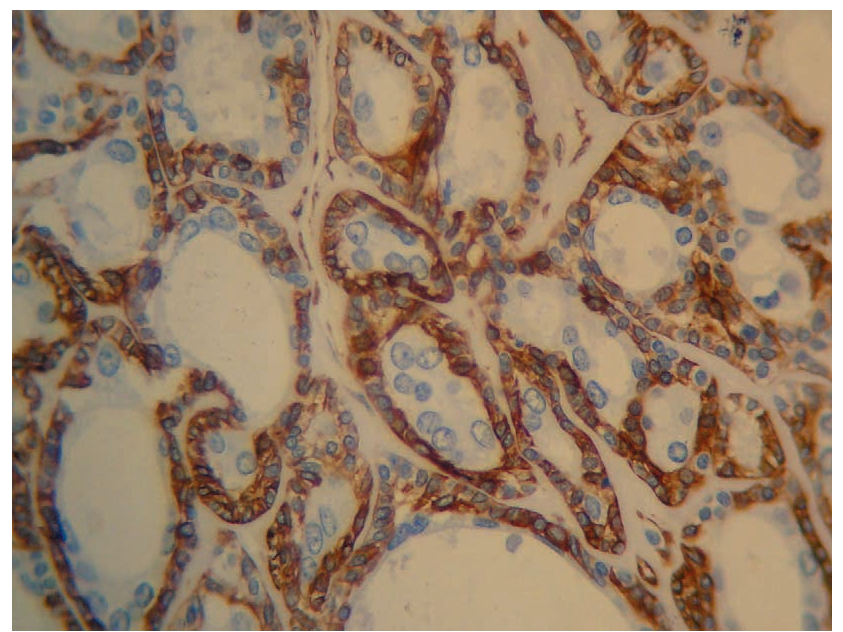

Fig. 9. Células mioepiteliales con inmunomarcación positiva para a-SMA.400x.

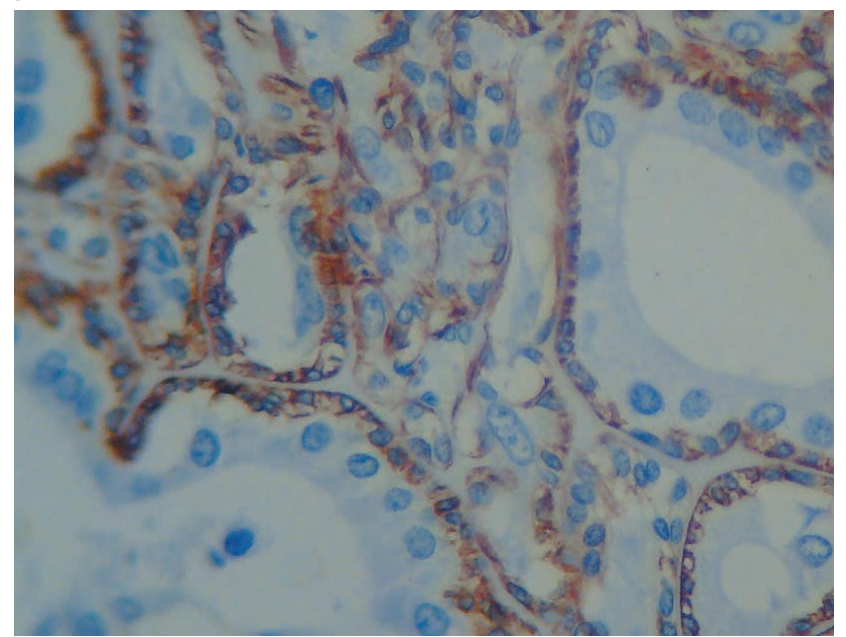

Fig. 10.Células mioepiteliales con inmunomarcación positiva para S-100.400x.

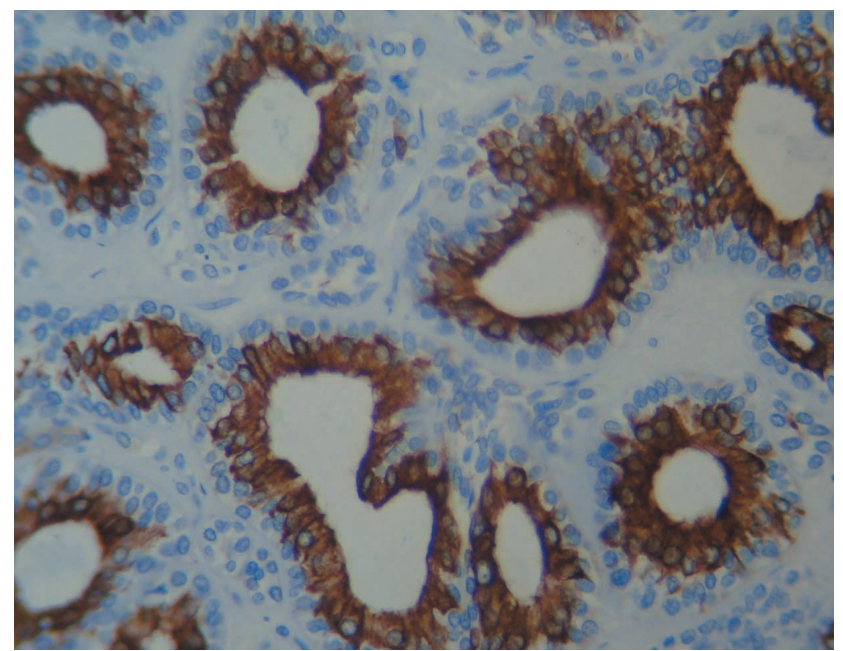

Fig. 11.Células epiteliales luminales positivas para CK de bajo peso molecular. 400x.

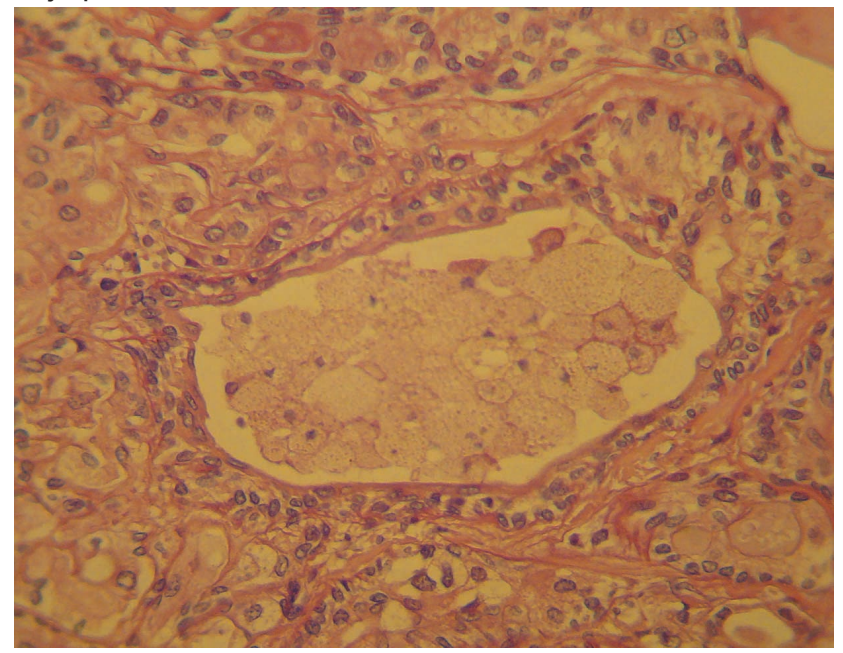

Fig. 12. Areas de diferenciación sebácea con nidos de sebocitos de citoplasma pálido con múltiples vacuolas y núcleos picnóticos. Coloración H/E. 400x.

\section{DISCUSION}

El diagnóstico histológico de CEM se basa en la identificación de dos tipos celulares, las células epiteliales y mioepiteliales (Ellis \& Auclair, 2008).

Técnicas como la inmunohistoquímica y la microscopía electrónica permiten confirmar el diagnóstico de los dos tipos celulares (Azúa Romero et al., 2001; Munot et al., 2003; Ellis \& Auclair, 2008).

En el caso que presentamos el estudio histoquímico muestra que las células eosinófilas centrales son CK y EMA positivas debido a su naturaleza 
epitelial (M'Sakni et al., 2007). Las células claras periféricas presentan marcación positiva para a -SMA y proteína S-100.

Se considera que el CEM es un tumor epitelial con grado histológico de malignidad bajo. Algunos autores, como Senis Segarra et al. (2002) plantean la necesidad de reconsiderar este concepto debido a su alta incidencia de recurrencias, metástasis a distancia en un $18 \%$ de los casos y mortalidad en un $8 \%$. En consecuencia, su inclusión como neoplasia maligna se debe basar en su evolución clínica y no en su aspecto histológico.

El diagnóstico de nidos celulares con diferenciación sebácea nos lleva a considerar este caso como muy interesante teniendo en cuenta la escasa bibliografía que menciona esta característica estructural.

Según la bibliografía consultada (Shinozaki et al., 2008) las neoplasias sebáceas primarias son extremadamente raras en las glándulas salivales. Por el contrario, los sebocitos se pueden observar con frecuencia en el parénquima normal de estos órganos (Mariappan et al., 2004).

En cuanto al componente sebáceo del CEM, Shinozaki et al. (2008) mencionan que no se encuentran sus descripciones en publicaciones periódicas ni en textos específicos sobre patología de las glándulas salivales.

El diagnóstico diferencial entre CEM y carcinoma sebáceo salival primario se realiza por la ausencia de inmunomarcación mioepitelial positiva de este último (Shinozaki et al., 2008).

La presencia de células claras plantea realizar el diagnóstico diferencial con otros tumores de glándulas salivales que también muestran este tipo celular.

Maiorano et al. (1997) clasificaron a los tumores de glándulas salivales que presentan células claras en dos grupos: tumores monofásicos con células de origen ductal o mioepitelial y tumores bifásicos con células de origen epitelial y mioepitelial, fácilmente diferenciables con técnicas inmunohistoquímicas.

Dentro de los tumores benignos con células claras se incluyen el adenoma pleomorfo y el mioepitelioma. La presencia del primer tumor se descarta debido a la ausencia de áreas estromales con matriz condromixoide y con relación al mioepitelioma, este tumor está formado por una población celular monomorfa con ausencia de estructuras tubulares (Ellis \& Auclair, 2008).

En el grupo de tumores malignos de células claras se lo debe diferenciar del carcinoma de células acinares y carcinoma mucoepidermoide a células claras y carcinoma de células claras hialinizante (Ellis \& Auclair, 2008). Estos tumores, a diferencia del CEM, no muestran un componente celular bifásico característico.

Wang et al. (2002) compararon las características clínico - patológicas de tres tipos de tumores salivales primarios de células claras, carcinoma a células claras, CEM y carcinoma mioepitelial a células claras, para investigar su relación con respecto a la diferenciación mioepitelial y ofrecer una aproximación diagnóstica para distinguir estas entidades.

Los autores demostraron que el carcinoma a células claras tiene predilección por sitios intraorales mientras que el CEM lo tiene por la glándula parótida y que los tres tipos tumorales estudiados tienen una tendencia a la recurrencia locorregional.

Wang et al. (2002) no encontraron evidencias precisas de diferenciación mioepitelial en el carcinoma a células claras, lo que indica que esta neoplasia sería morfogenéticamente diferente a los otros analizados, tumores éstos que tienen como requisito para su diagnóstico la presencia de células mioepiteliales. Por consiguiente, estos investigadores concluyen que la ausencia de diferenciación mioepitelial en el carcinoma de células claras es consistente con el concepto de que este tumor es histomorfogenéticamente diferente del CEM y no tan solo una variante monomorfa. En un trabajo que data del año 1999. Thiébault et al. (1999) mencionan que para el diagnóstico diferencial del CEM no sólo se deben tener presentes los tumores a células claras de las glándulas salivales sino también el carcinoma metastático renal .

Gimeno Aranguez \& Lacruz Pelea (2001) destacan que las glándulas salivales pueden ser órganos blanco de tumores de células claras, principalmente el carcinoma de células renales, el melanoma, y los tumores de células claras de hígado, tiroides, próstata e intestino, tumores poco frecuentes pero que se deben considerar en el diagnóstico diferencial.

El tratamiento de este tumor es quirúrgico y cuan- 
do los márgenes quirúrgicos son dudosos se realiza radioterapia postoperatoria (Senis-Segarra et al, 2002). Se deben realizar exploraciones clínicas periódicas, técnicas de imagen y citología por punción para el diagnóstico de las recidivas locales (Gimeno Aranguez \& Lacruz Pelea, 2001).
Se concluye que los estudios inmunohistoquímicos confirman la presencia de dos poblaciones de células tumorales: ductales y mioepiteliales. Además, las células claras mioepiteliales constituyen un elemento importante para el diagnóstico diferencial entre CEM sebáceo y adenocarcinoma sebáceo.

SAMAR, M. E.; ÁVILA, R. E.; FONSECA, I. B. \& FERRARIS, R. V. Sebaceous epithelial myoepithelial carcinoma of parotid: Histopathological and immunohistochemical analysis. Int. J. Odontostomat., 4(2):189-196, 2010.

ABSTRACT: Epithelial myoepithelial carcinoma (EMC) of the salivary glands is an uncommon, low grade, biphasic neoplasm. We reported a rare case of sebaceous EMC of the parotid gland in a man who had a left parotidectomy because of a tumoral formation apparently encapsulated. For the histopathological and immunohistochemical study the material was stained with $\mathrm{H} / \mathrm{E}$, Masson and Dane/Alcian blue trichrome, PAS/H, Toluidine blue, epithelial membrane antigen (EMA), cytokeratins (CK) of low molecular weight, a-smooth muscle actin (a-SMA) and S-100. Histologically, the tumor showed a multinodal pattern with tumoral nests constituted by ducts with a double cell lining: a- luminal cuboidal eosinophilic cells; badluminal clear cells. The inner cells were positively marked with antibodies for EMA and CK. It was observed positive immunoreactivity for a-SMA and S-100 in clear cells. It was observed areas of sebaceous differentiation inside the tumoral mass. Immunohistochemical studies confirmed ductal tumoral and myoepithelial cells presence. Besides, myoepithelial clear cells aided differential diagnosis between sebaceous EMC and sebaceous adenocarcinoma.

KEY WORDS: parotid, epithelial myoepithelial carcinoma, histopathology, immunohistochemistry.

\section{REFERENCIAS BIBLIOGRÁFICAS}

Angiero, F.; Sozzi, D.; Seramondi, R. \& Valente, M. G. Epithelial-myoepithelial carcinoma of the minor salivary glands: Inmunohistochemical and morphological features. Anticancer Res., 29:47039, 2009.

Azúa Romero, J.; Usón Bounthelier, T.; Alvarez Alegret, R. \& Martínez Tello, E. Carcinoma epithelial mioepitelial versus mioepitelioma con componente ductal recidivante. IV Congreso Virtual Hispanoamericano de Anatomía Patológica. conganat.uninet.edu/IVCVHAP, 2001.

Batzakis, J. G.; el-Naggar, A. K. \& Luna, M. A. Epithelialmyoepithelial carcinoma of salivary gland. Am. Otol. Rhinol. Laryngol., 101:540-2, 1992.

Doganay, L.; Bilgi, S.; Ozdil, A.; Yoruk, Y.; Altaner, S. \& Kutlu, K. Epithelial-myoepithelial carcinoma of the lung. A case report and review of the literature. Arch. Pathol. Lab. Med., 127:177-80, 2003.

Donath, K.; Seifert, G. \& Schmitz, R. Zur diagnose and ultrastruktur des tubularen speichelgangkarzinoms. Epithelial-myoepitheliales schaltusuckkarzinom. Virchows Arch. A. Pathol. Pathol. Anat., 256:16-31, 1972.
Ellis, G. L.; Auclair, P. L. Atlas of tumor pathology. Tumors of the salivary glands. AFIP ed., Washington DC,2008.

Erkan, A. N.; Bal, N.; Caylakli, F. \& Kirog hu, F. Epithelial-myoepithelial carcinoma of the submandibular gland: a case report. Kulak Burun Bogaz Ihtis. Derg. 17:167-70, 2007.

Gimeno Aranguez, M. \& Lacruz Pelea, C. Características citológicas por PAPF del carcinoma epitelialmioepitelial de parótida. Rev. Esp. Patol., 34:51-7, 2001.

Jain, M.; Thomas, S. \& Sing, S. Epithelial-myoepithelial carcinoma of minor salivary gland- low grade malignant tumor presenting with nodal metastasis. Indian J. Pathol. Microbiol., 49:399-401, 2006.

Kawahara, A.; Harada, H.; Yokayama, T. \& Kage, M. p63 expression of clear myoepithelial cells in epithelial-myoepithelial carcinoma of salivary gland: a useful marker for naked myoepithelial cells in cytology. Cancer, 105:240-5, 2005.

Kumai, Y.; Ogata, N. \& Yumoto, E. Epithelialmyoepithelial carcinoma in the base of the tongue: 
a case report. Am. J. Otolaryngol., 27:58-60, 2006.

Kuran, G.; Sagit, M.; Akin, G.; Hucumenoghi, S.; Ocal, B G. \& Celik, S. Y. Bilateral epithelial-myoepithelial carcinoma: an extraordinary tumor of the paranasal sinuses. Skull Base, 18:145-50, 2008.

Lampe, H.; Ruby, R. R.; Greenway, R. E.; DeRose, G. \& Wysocki, G. P. Epithelial-myoepithelial carcinoma of the salivary gland. J. Otolaryngol., 13:247$51,1981$.

Lee, H. M.; Kim, A. R. \& Lee, SH. Epithelialmyoepithelial carcinoma of the nasal cavity. Eur. Arch. Otorhinolaryngol., 257:376-8, 2000.

M'Sakni, I.; Laabidi, B.; Bougrine, F.; Sabbegh-Znaidii, N. \& Benzarti, S. Carcinoma épithélial-myoépithélial de la cavité nasal. Ann. dÓtolaryngol. Chir. Cervicofac., 124:228-31, 2007.

Maiorano, E.; Altini, M. \& Favia, G. Clear cell tumors of the salivary glands, jaws and oral mucosa. Semin. Diag. Pathol., 14:203-12, 1997.

Mariappan, M. F.; Fadare, O. \& Jain, D. Sebaceous differentiation in salivary glands. Arch. Pathol. Lab. Med., 128:245-6, 2004.

Maurer, M. H.; Gartenschläger, S. \& Dietrich, C. Giant epithelial-myoepithelial carcinoma of the parotid gland. Clin. Imaging., 33:237-9, 2009.

Mikaelian, D.O.; Contrucci, R.B.; Batsakis, J.G. Epithelial-myoepithelial carcinoma of the subglottic region: a case presentation and review of the literature. Otolaryngol. Head Neck Surg., 95:1046, 1986.

Munot, P. C.; Ganvir, S. M.; Dolas, R. S. \& Hazarey, V. K. Epithelial-myoepithelial carcinoma of palate: a case report. J. Oral Maxillofac. Pathol., (serial online) 7:54-6, 2003.

Okudela, K.; Yazawa, T.; Tajiri, M.; Omori, T.; Takahashi, K.; Woo, T.; Shimoyamada, H.;Ogawa, N. \& Kitamura, H. A case of epithelial-myoepithelial carcinoma of the bronchus. A review of reported cases and a comparison with other salivary glandtype carcinoma of the bronchus. Pathol. Res. Pract., 15:121-9, 2010.

Puri, T.; Singh, K.; Sharma, D. N.; Khurana, N.
Epithelial-myoepithelial carcinoma of the base of tongue: pathology and management. Indian $\mathrm{J}$. Cancer, 41:138-40, 2004.

Robinson, R. A. Head and neck pathology. Atlas for histologic and cytologic diagnosis. Lippincott Williams \& Wilkins, Filadelfia, 2010.

Samar, M. E.; Avila, R. E. \& Esteban, F. J. Técnicas histológicas. Ed SeisC, Córdoba, 2004.

Seifert, G. \& Sobin, L. H. Histological typing of salivary gland tumours. World Health Organization. International histological classification of tumours. $2^{\circ}$ ed., Springer-Verlang, New York, 1991.

Senis-Segarra, L.; Sahuquillo-Arce; Davo, E.; HamadArcis, R. P.; Floria-García, L. M. \& Barquero Ruiz, M. C. Salivary gland epithelial- myoepithelial carcinoma: Behaviour, diagnosis and treatment. Med. Oral, 7: 391-5, 2002.

Sheetala, R. R.; Barnes, E. L. \& Hunt, J. L. Epithelialmyoepithelial carcinoma: A review of clinic pathologic spectrum and inmunophenotypic characteristics in 61 tumors of the salivary glands and upper aerodigestive tract. Am. J. Surg. Pathol., 31:44-57, 2007.

Shinozaki, A.; Nagao, T.; Endo, H.; Kato, N.; Hirokawa, M.; Mizobuchi, K.; Masuda, S.; Sano, K.; Izumi, M.; Fukuyama, M. \& Mukai, K. Sebaceous epithelialmyoepithelial carcinoma of the salivary gland: clinocopathologic and inmunohistochemical analysis of 6 cases of a new histologic variant. $A m$. J. Surg. Pathol., 32:913-23, 2008.

Taıs, A.; Yag־iz, R.; Altaner, S.; Koten, M. \& Karasalihog hu, A. E. A case of epithelial myoepithelial carcinoma of the parotid gland. Kulak Burun Bogaz Ihtis Derg., 10:171-4, 2003.

Teppo, H. \& Paronen, I. Epithelial-myoepithelial carcinoma in minor salivary gland of the hard palate. $J$. Craniofac. Surg., 19:1689-91, 2008.

Thiébault, S.; Mogras, A.; Brun, I.; Hamel, S.; Colson, A.; Rozan, S. \& Laedlein-Greilsammer, D. Epithelial-myoepithelial carcinoma of the salivary glands: report of a case. Ann. Pathol., 19:30-2, 1999.

Tralongo, V. \& Daniele, E. Epithelial-myoepithelial car- 
cinoma of the salivary glands: a review of literature. Anticancer Res., 18 (1B):603-8, 1998.

Ustinova, E. L.; Gonevich, R.; Smirnova, E. S. Epithelial-myoepithelial carcinoma of the salivary glands. Arkh. Patol., 66:47-50, 2004.

Wang, G.; Brandwein, M.; Gordon, R.; Robinson, R.; Urken, M. \& Zarbo, R. J. Primary salivary clear cell tumors- a diagnostic approach: a clinic pathologic and inmunohistochemical study of 20 patients with clear cell carcinoma, clear cell myoepithelial carcinoma and epithelial-myoepithelial carcinoma. Arch. Pathol. Lab. Med., 126:676-85, 2002.

Dirección para correspondencia:

Prof. Dra. María Elena Samar

II Cátedra de Histología, Embriología y Genética

Facultad de Ciencias Médicas

Cátedra A de Histología y Embriología

Facultad de Odontología

Universidad Nacional de Córdoba

ARGENTINA

Email: samarcongreso@gmail.com

Recibido : 15-08-2010

Aceptado: 23-08-2010 